\title{
Perspective
}

\section{Mitral Valve Repair Operations - Aspects of Risk and Uncertainty}

\author{
John Mangan* \\ Australian Institute for Business and Economics University of Queensland, Australia
}

*Corresponding author: John Mangan, Australian Institute for Business and Economics University of Queensland, Australia.

Received Date: April 07, 2020

Published Date: April 27, 2020

\section{Introduction}

About 18 months ago, I received a shock during a routine health examination. I had noises coming from my heart. It was subsequently diagnosed as a (mitral prolapse regurgitation at severity level 3 from 4). Yet, apart from some tiredness during the day, I was asymptomatic. As an economist, with some knowledge of risk and probabilities, I needed to make some decisions regarding timing of treatment, form of treatment, expectations of outcome and the possibility of ongoing treatment. Of course, it could not be purely an analytical exercise, health and possibly life itself, were on the line but the economics and statistics training took hold. Below I outline the decision process.

\section{To treat or not?}

I was seemingly in good health, playing active sport and recorded a very low (zero) reading on a calcium test. Operations always bring risk and I was informed, that people with my degree of prolapse often continued-on without an operation. On the other hand, medical advice indicated that treatment sooner than later increased the chances of success, and that level 3 cases eventually needed to be treated sometime in the future. In essence, the probabilities were coming around towards intervention sooner than later. It was then my economics training took over and I remembered the classic Frank Knight paper on Risk and Uncertainty and Profit. Knight was among the first to set out the distinctions between risk and uncertainty. He distinguishes uncertainty from risk. Risk is technically defined as a situation where the possible consequences of the decision that is to be made are known. By contrast, true uncertainty may be defined as the possibility of alternative outcomes whose probabilities are not capable of measurement. I faced both risk and uncertainty. The risk (in aggregate), was fairly well known from recent aggregate studies of successful operations from the Mayo Clinic [1]. Then the uncertainties entered the equation. There was no guarantee that the leaky valve could be repaired. It may need to be replaced, but this decision would only come into play only after the operation had begun.

Almost all studies indicated that repair was better than replacement (Oliveria and Antunes, 2006 [2]). This is because under the repair scenario, there is less chance of the need for follow up surgery and a requirement of lifetime medication. Prior diagnosis will not reveal the need for repair and so my uncertainty about outcome soon became ambiguity as defined by Savage [3].

Savage assumed that it is possible to take convex combinations of decisions and that preferences would be preserved. So, if a person prefers $\mathrm{x}\left(=\mathrm{x}_{\mathrm{i}}\right)$ to $\mathrm{y}\left(=\mathrm{y}_{\mathrm{i}}\right)$ and $\mathrm{s}\left(=\mathrm{s}_{\mathrm{i}}\right)$ to $\left.\mathrm{t}\left(=\mathrm{t}_{\mathrm{i}}\right\}\right)$ then that person will prefer

$$
\lambda x+(1-\lambda) s \text { to } \lambda y+(1-\lambda) t \text { for any } 0<\lambda<1
$$

In this case, I preferred repair ( $\mathrm{x}$ ) to replacement $(\mathrm{y})$ and minimal invasive surgery $(\mathrm{s})$ to open heart surgery $(\mathrm{t})$.

My best-case scenario was x-s, the worst was y-t but I could end up with x-t or y-s. According to Savage, my uncertainty had passed to ambiguity and to advance. I could choose either adverse ambiguity, deciding if it was still desirable even under the worse scenario [4] or Savages "sure thing" principle, whereby I would take the optimistic view that the outcome will be the most desirable. Having opted for minimal invasive, the uncertainty revolves around the repairability of the leaky valve (x-s) or need to be replaced? As well, further study of the topic revealed that $30 \%$ of patients using this treatment suffered atrial fibrillation, which if uncontrolled could require a pacemaker to be fitted. Would I be one of those $30 \%$ ? 


\section{Open heart or minimal invasive surgery?}

Two alternative procedures were available [5]. The minimal invasive technique and the more traditional open-heart surgery. To most, the minimal invasive technique seems more appealing to the patient as it involves less physical disruption, can be robot assisted and has a lower hospital duration time. Offsetting this was the increased risk associated with relatively new techniques. I chose minimal invasive surgery acting upon advice from The Swiss Medical Weekly (2012) and PubMed (2011) [6].

"Modern repair techniques such as neo-chord implantation with the loop-technique combined with minimally invasive access routes result in low mortality and morbidity and short hospital stay as well as high patient approval" (Sunderman, Falk and Jacobs, 2012).

Risk profiles between the two techniques are similar, so we were back to uncertainty and in particular ambiguity about the benefits of the more proven method against the advantages of a less intrusive and quicker healing procedure. I went for "sure thing" or optimistic ambiguity, choosing what to me was the more palatable technique on the assumption that the risk factors were relatively equal between the two options.

\section{Choice of surgeon?}

In making such a choice, risk and uncertainty again were intermingled. In Australia, surgeons do not publish success rates. If we assume that, on average doctors, are relatively similarly skilled) then the success rate of the procedure overall should be a good proxy. Unfortunately, doctors are not equally skilled and in the absence of performance monitors, the next best means of rational selection is through word of mouth and the reputation of the facility. I did this by visiting two separate cardiologists and getting their recommendations. Fortunately, their advice steered me in the same direction.

\section{Result}

Medical procedures and their aftermath are classic mixtures of risk and uncertainty within which prospective patients need to navigate. Most medical procedures are repeated trials, with known success or failure probabilities. Therefore, in aggregate a patient has a good idea of the risk of a procedure. However, for each person, the procedure is individualized; uncertainty enters through choices around the timing of operation, choice of technique, choice of doctor and location and best means of recovery. Without reasonable approximations of outcome, this uncertainty leads to ambiguity and possibly non- optimal outcomes. In such cases, the best form of decision rule is to determine the worst, best and most likely outcomes and see which of these fit within your risk portfolio. In my case, I fitted the average patient stereotype; successful repair, suffered atrial fibrillation and discharged within 10 days. As an intending and then actual patient, I needed to make a number of decisions that had various and substantially different outcomes. Published data are aggregate in nature and do not address the many uncertainties facing individuals in ex-ante, pre-operation situations. In assessing the real risk, the economic and statistical principles can be adapted to transform uncertainty into acceptable risk.

\section{Acknowledgement}

None.

\section{Conflict of Interest}

No conflict of interest.

\section{References}

1. Estimated at $95 \%$ as long as I fitted in the average value parameters.

2. Olivera J, Antunes M (2006) Mitral valve repair is better than Replacement. British Journal of Medicine 3(1): 12.

3. Savage, L (1954) The Foundations of Statistics, Wiley, New York

4. Al-Najjar A, Weinstein J (2009) The Ambiguity Aversion Literature: A Critical Assessment. Economics and Philosophy 25: 249-284.

5. Cheng D (2011) Minimally Invasive versus conventional open valve surgery: a meta -analysis and systematic review. Innovations 6(2): 84103.

6. Sundermann S, Falk V, Jacobs S (2012) Mitral Valve ReconstructionTiming, Surgical Techniques and Results. Swiss Medical Weekly pp. 142. 